\title{
Research on Food Safety Supervision Model in China
}

\author{
Tiantian Zhao \\ Southwest University for Nationalities \\ E-mail: 835436663@qq.com
}

\author{
Jiayi Wang \\ Southwest University for Nationalities \\ E-mail: cissyfannn@163.com
}

\author{
Wenjing Chen \\ Southwest University for Nationalities \\ E-mail: 1069232790@qq.com
}

\begin{abstract}
Food safety is very important, for it is related to the health of people, the social harmony and stability, the development of national economy and even the survival of our nation. But in recent years, our food safety problems appear frequently, and it not only brings great harm to the people's health and safety, but also seriously affects our country's politics, economy, and culture. This paper summarizes the current situation and major problems in our food safety supervision model, and analyzes the causes of these problems. Meanwhile it introduces the experiences of foreign countries in combination with the fundamental realities of our country, and then put forward some suggestions and countermeasures to transform the food safety supervision model in our country.
\end{abstract} Law

Keywords-food Safety; Supervision Model; Administrative

\section{THE PROBLEMS AND REASONS IN CHINA'S FoOD SAFETY SUPERVISION MODEL}

\section{A. The Current Situation of China's Food Safety Supervision Model}

"Food Safety Law" was passed and announced in the seventh meeting of the Standing Committee of 11th National People's Congress of the People's Republic of China on February 28, 2009, and has come into effect since June 1, 2009. It marked China's food safety supervision has entered a new era. However, view from actual execution, we still use the general pattern of segmented supervision that we have used in food market over the years and there is no much change. Therefore, we can see that, our "Food Safety Law" does not make substantial change on the food safety supervision. In fact, we are still using the general pattern of segmented supervision. Although we seek to establish the all-round supervision system in the whole course in the legislative intent, we have not yet established an effective and comprehensive supervision system in practice. With absence of comprehensive supervision, it will inevitably leads to problems in connection of supervision links. In addition, we have insufficient legal basis and support from relevant mechanisms and institutions in the coordination of each links, so that there are a lot of loopholes and regulatory failure in the implementation of the food market supervision.

\section{B. The Problems in the Food Safety Supervision Model in China}

1) Overlapping supervision. "Food Safety Law" did not achieve the all-round mechanism combining segmented supervision with comprehensive supervision. We still use the general pattern of segmented supervision and lack comprehensive supervision, which first leads to the ambiguity of power and duties of supervision departments. There are many repetitions of power and duties in many fields. Some departments attach importance to departmental interests, and have less communication and cooperation with other departments. In the supervision process, they pick the fat or choose the lean. In other words, they often choose easy, profitable, and favorable supervision activities, while they escape or avoid choosing hard complicated supervision activities. As a consequence, we have a lot of supervision departments in the food safety field, but many departments take similar actions toward same target. It not only makes the operators struggling to cope, also has caused the waste of administrative resources.

Overlapping supervision is also likely to cause information confusion. The supervision departments, especially some local departments have different standards and technological means, so data obtained and evaluation results and treatment suggestions are greatly different to each other. It causes information confusion among food market operators and consumers. These administrative organs are unable to shoulder the responsibility of disclosure of authoritative information, thus causing greater confusion in food market with asymmetry information.

2) The blind area. With the absence of effective comprehensive supervision, the segmented supervision model has another drawback that it is easy to cause the emergence of blind area. For example, Sanlu Event shocked the country. The main reason for the continuous spread of its harm is the problem of blind area. All fresh milk for Sanlu's dairy products was purchased from dairy farmers. For the convenience of purchase, all milk production regions set up their milk stations. But it is impossible to determine their regulatory bodies. The health authorities 
thought milk was a primary agricultural product, so it should be supervised by the departments of agriculture. However, the departments of agriculture thought fresh milk was raw material of dairy products in light industry, so it should be supervised by the Light Industry Federation. The Light Industry Federation thought fresh milk was raw food material, and the health departments should be responsible for its safety. These departments passed the buck to each other, and there was no one unified regulatory body to supervise milk stations all over the country. Melamine is insoluble in water. It is a relative advanced technology by adding melamine into milk products to enhance the protein content. Most of dairy products were added with "protein" in milk stations. Could workers of milk stations develop this technology? It only could be developed with professional lab resources. This only shows relevant enterprises have detected the presence of regulatory loopholes and take advantage, to avoid the supervision of the governments, seek ill-gotten wealth, causing the damage of the public's health.

Sanlu Event has a very bad effect, even it can be written down in the history. Before that there have been several large-scale food safety incidents, but their harm and range could not be compared with Sanlu Event. Sanlu Event can be described as the watershed in China's food safety history. After this event, the majority of people consider food safety as a big deal, for it really is related to our life. The media also began to develop programs related to health and health maintenance, and the audience rating maintained high. However, the response of executive authorities on this issue was very unsatisfactory. The state had made severe punishment on the enterprises and individuals concerned, even relevant leading cadres of Shijiazhuang. However, after this storm, the governments no longer concern this problem. They do not take substantive reforms on the supervision of food safety, nor establish appropriate and effective regulatory mechanism. Although they have issued "Food Safety Law", they still use the general pattern of segmented supervision. The consequence of such an approach is the outbreak of food safety incidents one after another, and it is more and more frequent and serious. It is largely because that the segmented supervision has produced a lot of blind areas. So many supervision links are neglected and with no supervision, resulting in harmful effect. And the governments do not take any measure to supervise the blind areas that have been found. For example, from Sanlu Event till now, many milk stations all over the country are still in unsupervised state. It is such detestable they slack their duties and slight to take regulation with the risk of people's life. And the deepest reason is the unreasonable supervision model in our country.

3) Lack of supervision. It is no doubt that food safety problems are caused by some heartless enterprises. They want to reap huge profits regardless of the people's health and the violation of law. They have caused a disastrous effect and destroyed the order of food market. But the inaction and arbitrary conducts of China's administrative organs in the process of supervision have indulged such behaviors in a great extent. Especially some local administrative authorities fear to trace, understate even hide the truth of food safety hazard. It greatly misleads the public and increases the damage of a number of food safety events.

The regulatory mechanisms of all fields have some shortcomings, because the regulatory powers are still executed by a number of specific departments and individuals. If the interests of their own departments or the individual conflict with the interests of the public, they may choose to protect their interests. In addition, in case of lack of supervision, they probably choose to violate the public interests. So it is also very important to supervise the regulatory departments. It can help prevent the abuse of power and investigate supervision responsibilities effectively. It is the embodiment of power commensurate with responsibility.

\section{Reason Analysis}

There exist many problems in China's food safety supervision model. In fact, the fundamental reason is the defect of China's food safety supervision model. Although we seek to establish the all-round supervision procedure in the whole course in the legislative intent, we are still using the general pattern of segmented supervision in law and we have not yet established an effective and comprehensive supervision system in practice. It inevitably leads to problems of overlapping supervision links or non-connection of supervision links among departments, and confused disclosure of information. There are some more deep-seated reasons in our laws related to our country's food safety supervision, and these reasons are not only related to the non-establishment of a comprehensive supervision model, but also constantly enlarged defect of the current segmented supervision model. The reasons are as follows:

1) Unsound administrative legal system and the lack of basis on the achievement of supervision model. The issue of "Food Safety Law" has perfected work division of the food safety supervision departments. Their duties and responsibilities are clearer than before. It also has determined the direction to establish an all-round supervision model in the legislative intent. However, the unsound administrative legal system is still the most essential factor of the problems in our food safety supervision model.

In addition, our unsound administrative law system also has caused the occurrence of power incommensurate with responsibility of regulatory organs in the food safety supervision. China's food safety regulatory organs have the power to prevent food safety issues, and give supervision, management and punishment. But we lack legal basis on their responsibilities and responsibility-ascertaining model. Although "Food Safety Law" has stipulated some responsibilities mechanisms to supervision departments, these provisions are not clear and there is no specific mechanism design. "Regulations for the Implementation of Food Safety Law" has not stipulated the specific responsibility-ascertaining procedure and model. The legal basis for ascertaining both administrative responsibility and 
legal liability is not sufficient. If a body masters the power but not burdens explicit responsibilities, the inaction and arbitrary conducts of China's administrative organs are not surprising.

Based on this, with such defect in our legal structure, we can not provide a strong guarantee and support to the operation of the food safety supervision system and the supervision model. It is the most fundamental reason of the endless emerging problems in the food safety supervision model.

2) The improper distribution of administrative power and the disorder implementation of supervision model. The unsound administrative law system and the imperfect legal basis and even the lack of legal basis result in the defect in the food safety supervision model of China. On the basis of this, the improper distribution of administrative power has increased the seriousness of the problems due to the defect in China's food safety supervision model.

Our country lacks a strong authority to lead and coordinate the food safety supervision departments in accordance with the statutory powers, while all food safety supervision departments have their own powers and act of their own free will. This kind of administrative power structure will inevitably produce conflicts between departments due to power intersection and supervision overlap. On contrary the lack of implementation of administration power may results in non-connection of supervision links among departments and the appearance of blind area. We do not have a supervision authority to guide and coordinate all supervision departments in the administrative system, so the supervision departments lack "to be supervised" according to the principal of the administrative bodies' grade and power, and are with no restriction in the execution of power, so that we can not ascertain their responsibilities effectively. Therefore, the unsound administrative law system is the theoretical reason of problems in our country's food safety supervision model, and the improper distribution of power is the practical reason of problems in our country's food safety supervision model.

3) Lack of participants in food safety supervision. In China's current food safety supervision model, there are a lot of problems, such as supervision overlap, blind area and lack of supervision on supervision departments. Another important reason for these phenomena is the lack of participants in our food safety supervision. It is the government to play the role of supervision in our food safety supervision to a great extent. Social organizations or the public do not participate in it. Although it is more reasonable for the government to play the role of supervision compared with social organizations and the public, for it is easy for the government to master some professional technologies and resources, there is possibility of the failure of the government. At this time, the participation of social organizations and the public are especially important. The government plays the dominant role in food safety supervision, and social organizations as a social group and the public, as a basic unit of society also shall also play their roles. However, due to the large government in China since ancient times, the social forces appear to shrink. Social organizations and the public lack awareness of self-protection and social participation, so that social forces can not compensate for these defects in the failure and unreasonable supervision of the government.

The lack of participation of the public in supervising food safety problems seems more serious in our country, which is partly due to the insufficient popularity of China's food safety knowledge. Many people have the concept of "we will not sick even if we eat unclean food", and it is because of the current political system. Many people think the food safety supervision is the responsibility of the government, and it is not their business, so that consumers, as basic unit, can not play a positive role in China's food safety supervision. When consumers find some food safety problems, many of them choose to pay to the problem only themselves and not to report to the regulatory authorities. So many problems that should have been found early, dealt and solved on time, have produced a greater harm later.

Therefore, although the government is in a dominant position in food supervision, the participation of social organizations and the public is also very important, because they can carry out supervision on food safety in a wider range and more basic level. The current supervision model lays too much emphasis on the segmented supervision and lacks comprehensive supervision, so it brings a lot of difficulty in connection of supervision links. In this case the participation of the social power is extremely important, for it can make up for defects in the government's food safety supervision work and reduce the harm of food safety problems to the minimum due to the failure of market or the government. Moreover, the participation of social organizations and the public in the food safety supervision is in favor of optimizing the pattern of the administrative body and administrative counterpart's position, and can strengthen the power to ascertain the responsibility of the regulatory authorities. At same time, it can make cost index for administrative counterpart to get administrative or judicial remedy more reasonable. In this way change the non-equivalent relationship of administrative power and responsibility of administrative counterpart in the current pattern. We rely on the administrative body too much but pay a little attention on administrative counterpart. We should put the power of the administrative body under the supervision of administrative counterpart.

\section{SUGGESTIONS AND COUNTERMEASURES ON THE TRANSFORMATION OF CHINA'S FOOD SAFETY SUPERVISION MODEL}

\section{A. Revising "Food Safety Law" and Establishing a Unified Comprehensive Supervision Model}

China's "Food Safety Law" has established the Food Safety Commission of the State Council as coordinating body, aiming at making up for the regulatory failures caused by segmented supervision. However, this system can not solve all kinds of regulatory problems caused by the segmented supervision. It is only a remedy and coordination to these problems, and the power and responsibilities of the Food Safety Commission of the State Council are stipulated 
in the law but indefinitely. Its focus is on major food safety issues, and its role of supervision on daily food safety is really questionable.

China's food safety supervision model is still in the ignorant and reform period. The history of our food safety supervision system is not long, and we do not have a lot of potential historical leftover problems to resist the reform. The reform in adjustment period will be easy than that in mature period. We can establish a sound model as long as we have a sound legislative system.

\section{B. Approaches to Improving the Related Administrative Law System to the Food Safety Supervision}

The unsound administrative law system related to China's food safety supervision is the basic cause of the imperfect food safety supervision model in China. Although the issue of "Food Safety Law" has provided a relatively full legal basis for our food safety supervision, it has a few of provisions on power, responsibilities and mechanism of food safety administrative authorities and the provisions are also very vague. In addition, there exist certain problems in legislative system, so that it can not provide legal basis for regulatory bodies to execute authority and bear responsibilities. In current food safety supervision model, most of the duties are according to some administrative normative documents, and many of them do not fit for laws, and it has brought a lot of problems on food safety supervision. Some departments for the benefit of their own interests only focus on the interests of their departments in the implementation of administrative regulations, and even infringe the interests of other departments, which seriously affect the exercise of the power of other departments. These problems are due to the unsound administrative law system. We have no specific supervision on these administrative organs. Although the administrative normative documents can play a temporary role, it can not play a long-term effect, and its characteristic of flexibility is both an advantage and a disadvantage. It enables to make adjustment at any time, but it lacks authority, stability and can be used as a long-term legal basis.

\section{Promoting the Establishment of a Unified Regulatory Body Step by Step}

The selection of food safety supervision model comes down to the distribution of the administrative power view from the level of administrative organ. If the distribution of the administrative power is improper, the establishment of any perfect supervision model has no meaning. It is an essential condition for the transformation of our food safety supervision model to establish a unified comprehensive regulatory body and concentrate all administrative authorities of food safety supervision field on this body, which is in line with the government's policy of the promotion of reform, but also conducive to the development of China's food safety supervision work.

\section{Establishing a Food Safety Supervision Accountability System}

Food safety supervision is considered as an important administrative function and regulatory activity. Food safety issues involve in public interests and have its special effects on people. If the administrative organs neglect their duties in this aspect, its harmfulness will be extremely huge. Therefore, it is very necessary to establish a food safety supervision accountability system to guide supervision activities of the administrative organs and ascertain responsibilities.

To establish the supervision accountability system in fact is to strengthen the supervision on regulatory authorities, so that they dare not to despise the issues of food safety and shoulder responsibility carefully. It can avoid the failure of government due to dereliction of duty, ensure the realization of the food safety supervision model in our country and avoid problems that have appeared before in model selection and system design, and at same time encourage the participation of social forces.

\section{E. Establishing a Food Safety Infringement Remedy System}

Under China's current food safety supervision model, food safety remedy is very difficult. There is no unified policy. A problem often involves several departments, and functions and powers of many departments. We have no formal and authoritative legal basis, but needless to say the remedy system. Both the administrative remedy and judicial remedy should have a clear legal basis and implementation procedure, but they are not yet established in practice. China should pay more attention to and improve the judicial remedy and develop the food safety infringement administrative remedy.

\section{F. Establishing a Food Safety Information Disclosure System}

With any food safety supervision model, the disclosure of safety information is very important. If a country establish a unified comprehensive supervision model, the information disclosure of its regulatory organs help authorities of all levels exercise their duties and social forces participate in supervision. Our current segmented supervision model has produced a lot of problems, so it is necessary to establish the information disclosure system as soon as possible. The food safety information disclosure system should be based on the principle of emphasizing risk assessment. A systematic safety information release system is to release food safety information and give food safety hazard notification according to regions and grades. For example, the hazard can be divided into four grades of red, orange, yellow and green according to grades, and national level, provincial level and regional level according to regions. These notifications shall be approved by the national governments and released by key media, and be broadcast in a relatively stable and golden time period, to facilitate social organizations and the public to grasp the relevant information, clear security situation, and help them make corresponding preparation to deal with food safety issues. If units and individuals deliberately conceal and miss information or make a false report on safety 
information, they should be severely punished in order to stop the so-called behavior of "avoiding confusion and concealing information".

\section{G. Taking Measures to Encourage Social Forces to Participate in Supervision}

For the participation of social forces, if the governments do a good job in corresponding accountability, infringement remedy and the establishment of information release system, social forces will actively participate in the food safety supervision. After all it involves the vital interests of the public. And the government can also give reward to the organizations or individuals that report the food safety hazards or help regulatory organs solve food safety problems, and strengthen communication and coordination with social forces, guide social forces to participate in supervision, which will be a huge boost to the reform of China's food safety supervision model.

\section{REFERENCES}

[1] Edgar Bodenheimer. Nomology - Philosophy of Law and Legal Methods. China University of Political Science and Law Press, 1999.

[2] Roscoe Pound. Social Control Through Law - Task of Law, Commercial Press, 1984 edition.

[3] Zhang Wenxian. The Research on the Basic Category of Law. China University of Political Science and Law Press, 1993.

[4] Zhang Naigen. Western Philosophy of Law History. China University of Political Science and Law Press, 1999 edition.

[5] Montesquieu. The Spirit of the Laws. Commercial Press, 2009 edition.

[6] Chen Xiwen, Deng Nan. Research on China's Food Safety Strategies. Chemical Industry Press, 2004 edition.

[7] Xiong Wenzhao. The Principle of Modern Administrative Law. Law Press, 2000 edition

[8] Zhang Wenxian, editor in chief. Nomology. Higher Education Press, 2011.

[9] Shi Xianming, editor in chief. Food Safety and Hygiene. Chinese Agriculture Press, 2009 edition.

[10] Edited by Zhejiang Research Institute of Standardization. The Basic Law and Research on Food Safety Management of the European Union, China Standard Press, 2007.

[11] Luo Haocai and et al. The Balance Theory of Modern Administrative Law. Peking University Press, 2003 edition.

[12] Jiang Ming'an, editor in chief. Administrative Law and Administrative Procedure Law. Peking University Press, 2011.

[13] Li Changiian \& Zhang Feng. Social Supervision - Research on China's Food Safety Supervision Model. Journal of Guangxi University (PHILOSOPHY AND SOCIAL SCIENCE EDITION), 2006, No. 5, 51 54.

[14] Chen Weikang \& Luo Le. Research and Enlightenment of Developed Countries' Food Safety Supervision. Guangdong Agricultural Sciences, 2009, No. 8, $229 \sim 232$.

[15] Han Zhongwei \& Li Yuji. From Segmented Supervision to Administrative Power Balance Supervision - Construction of Food Safety Supervision Model in China. Search, 2010, No. 6, $159 \sim 161$.

[16] Xu Jieyun. Discussion on the Food Safety Supervision Model in China. Social Sciences (New Theory Version), 2001, No. 3, 159 161

[17] Wang Yue. Research on the Food Safety Supervision Model and Institutional System in China. Master's Thesis of Law School of Huazhong Agricultural University.

[18] Food Safety Law of the People's Republic of China was passed in the seventh meeting of the Standing Committee of 11th National People's
Congress of the People's Republic of China on February 28, 2009, and has come into effect since June 1, 2009.

[19] General Food Law of European Union was passed by the European Parliament and the European Council of the European Parliament and the European Union Council on January 28, 2002, and has come into effect since February 21, 2001. 